\title{
Dual Epidemics of Club Drug Use and Sexually Transmitted Infections among Chinese Female Sex Workers: New Challenges to STI Prevention
}

\author{
Jing Li, Xiang-dong Gong, Xiaoli Yue, and Ning Jiang \\ Institute of Dermatology, Chinese Academy of Medical Sciences and Peking Union Medical College, Nanjing 210042, China \\ Correspondence should be addressed to Xiang-dong Gong; gxdchina@163.com
}

Received 10 February 2017; Accepted 24 April 2017; Published 30 May 2017

Academic Editor: Lucia Lopalco

Copyright (c) 2017 Jing Li et al. This is an open access article distributed under the Creative Commons Attribution License, which permits unrestricted use, distribution, and reproduction in any medium, provided the original work is properly cited.

\begin{abstract}
Objectives. To evaluate club drug use and its potential association with STI among female sex workers (FSWs) in China. Methods. From November 2008 to January 2009, participants were recruited at sex work venues in five cities for a questionnaire survey. Free testing for syphilis, Chlamydia trachomatis (CT), and Neisseria gonorrhoeae (NG) was provided. Logistic regression models were used to assess factors associated with club drug use and its association with STI. Results. A total of 1604 eligible FSWs were included. The overall prevalence of any STI infection and club drug use in the past 12 months was $22.6 \%$ and $7.4 \%$, respectively. STI prevalence was significantly higher among club drug users $(33.1 \%)$ than among nonusers $(21.7 \%, P<0.05)$. Multivariable logistic regression found that club drug use was associated with younger age (AOR 2.4, 95\% CI 1.0, 6.0), higher education, having injected drugs (AOR 24.4, 95\% CI 6.2, 96.8), and having had STI symptoms (AOR 2.2, 95\% CI 1.4, 3.4). Conclusions. Club drug use and STI were highly prevalent among FSWs in China, especially among young FSWs. Club drug users had more risk behaviors and higher STI rates. A coordinated risk reduction framework is urgently needed to address the dual epidemic of drug use and STI.
\end{abstract}

\section{Introduction}

Abuse of club drugs which refer to a group of synthesized drugs like methamphetamine and ecstasy has been on the rise around the world $[1,2]$. Club drug users can have heightened sex drive, prolonged sexual intercourse, and increased number of sex acts $[3,4]$. Studies in western countries showed that club drug use was associated with high-risk sexual behaviors and elevated risk of HIV and other sexually transmitted infections (STIs) among different risk groups $[5,6]$.

Like western countries, China has also seen a boom of club drug use in the past two decades [7, 8]. Club drugs are rapidly replacing heroin and becoming the most widespread illicit drugs in China $[8,9]$. Of the newly identified drug users in 2014, over half had used club drugs [9]. Given the predominant contribution of sexual transmission to HIV/STI epidemic in China [10], the use of club drugs among female sex workers (FSWs) and other risk groups could potentially fuel the epidemic. Recently, several Chinese studies reported the extent of club drug use among men who have sex with men $[11,12]$. And one available study conducted among FSWs in a northeastern city in China found an association between club drug use and syphilis infection $[13,14]$. Nevertheless, the prevalence and patterns of club drug use differ across populations and regions, and studies assessing club drug use and its association with HIV/STI risk remain scarce in China.

In the current study, we conducted a survey among FSWs in five cities in China to understand the scale of club drug use and assess its association with STI risk. The findings can provide evidence for designing and implementing more targeted sexual risk reduction interventions for FSW.

\section{Method}

2.1. Study Setting and Survey Procedure. The survey was conducted alongside routine sentinel surveillance work and the detailed procedure was reported elsewhere [15]. Briefly, between November 2008 and January 2009, a biobehavioral survey was conducted among FSWs at five national STI 
sentinel surveillance sites to reflect the geographic diversity in China. The five sites included Changchun in Jilin Province (northeast China), Lanzhou in Gansu Province (northwest China), Wuhan in Hubei Province (central China), Hangzhou in Zhejiang Province (east China), and Guangzhou in Guangdong Province (south China).

Health workers at sentinel sites mapped and routinely updated a list of sex work venues including information on venue types and the estimated number of FSWs at each venue. About 40 venues stratified by venue types were randomly selected from the list at each study site. If venue gate-keepers declined to participate, we would go to the next sametype venue on the list as a replacement. A maximum of 20 participants were included at each venue. Eligible participants were women who were 16 years old or above, self-reported to have exchanged sex for money in the past year, and were willing to undergo STI testing. After giving informed consent, participants were interviewed anonymously using a structured questionnaire to gather data on demographics and risk behaviors. All interviews were done in separate rooms or private space to ensure confidentiality. A small token (20 yuan, about 3 US dollars) was given as an incentive to those who agreed to take part in the survey.

The study was reviewed and approved by the Medical Ethics Committee of The Chinese Academy of Medical Sciences Institute of Dermatology and National Center for STD Control in Nanjing.

2.2. STI Testing. Free STI tests were provided to all participants. For syphilis testing, blood samples were collected and first tested for treponemal antibody using an enzyme-linked immunosorbent assay (ELISA). Positive ELISA tests were confirmed by nontreponemal toluidine red unheated serum test (TRUST, Rongsheng Biotechnology Company, Shanghai, China). Syphilis tests were performed at study sites according to the national algorithms and an external quality assurance procedure was in place to ensure favorable performance. Endocervical swabs were collected and tested for Neisseria gonorrhoeae (NG) and Chlamydia trachomatis (CT) by polymerase chain reaction (PCR, AMPLICOR, Roche, USA). The PCR tests were performed at National STD Reference Laboratory in Nanjing. All participants were informed of their syphilis testing results within a week and NG and CT results sometime later. Participants with positive results were referred to designated clinics for counseling, further evaluation, and possible treatment according to the national guidelines.

2.3. Measures. Club drug use was the primary outcome of interest. In the survey, FSWs were asked whether they had used methamphetamine, ketamine, and ecstasy/MDMA or to specify other club drugs if any in the past 12 months. Those who answered "yes" to one of the above drugs were coded as club drug users, while those who answered "no" to all drugs were coded as nonusers. For calculating prevalence, syphilis infection was defined as having positive results of both ELISA and TRUST tests, while CT or NG infection was defined as having a positive PCR testing result. STI infection was defined as having syphilis or CT or NG infection.
2.4. Data Analysis. All data from questionnaires and laboratory records were double-entered and checked for consistency using EpiData software. Chi-square tests were used to compare differences in club drug use and STI rates among different groups of FSWs. The variables associated with club drug use and STI were assessed first using univariate logistic regression models. Factors significant in univariate analysis $(P<0.10)$ were then assessed in multivariable regression analysis with backward stepwise elimination. All data were analyzed using Statistical Program for Social Sciences (SPSS, version 13.0, Chicago, IL) software.

\section{Results}

Among 1610 FSWs enrolled, 1604 provided cervical swabs and were included in the study. Of all participants, 356 FSWs were enrolled in Guangzhou, 308 in Hangzhou, 243 in Wuhan, 349 in Lanzhou, and 348 in Changchun. Overall, $118(7.4 \%)$ reported club drug use in the past 12 months. The frequency of reported club drug use was as follows: ketamine (77/1604, 4.8\%), methamphetamine (72/1604, 4.5\%), ecstasy/MDMA (30/1604, 1.9\%), and other drugs including marijuana and triazolam (5/1604, 0.3\%). The prevalence of any STI infection (syphilis or CT or NG positive) was $22.6 \%$ (326/1604). The prevalence of syphilis, NG, and CT infection was 5.4\% (86/1604), 5.5\% (89/1604), and $13.8 \%(222 / 1604)$, respectively.

Table 1 shows the difference of demographic and behavioral characteristics between club drug users and nonusers. Compared with nonusers, club drug users were more likely to be younger, unmarried, better educated, recruited from Guangzhou, based in night clubs or KaraOK, have injected drugs, and have STI diagnosis in the past 12 months.

Table 2 shows the factors associated with club drug use. In univariate analysis, factors like study sites, types of sex work venue, age, marital status, education level, injection drug use, and history of STI were significantly associated with club drug use. In multivariable analysis, factors retained significant association with more club drug use included being recruited from Guangzhou (adjusted odds ratio (AOR) $3.2,95 \%$ confidence interval (CI) $1.8,5.8$ ) and Wuhan (AOR $3.5,95 \%$ CI 1.8, 7.0) relative to Hangzhou, being based in night clubs or KaraOK relative to saunas (AOR 2.8, 95\% CI 1.5, 5.1), aged under 20 versus above 30 years (AOR 2.4, 95\% CI $1.0,6.0$ ), having middle (AOR 5.1, 95\% CI 1.5, 17.4) or high school education (AOR 6.8, 95\% CI 1.9, 23.6) versus primary school education, having injected drugs (AOR 24.4, 95\% CI $6.2,96.8$ ), and having had STI symptoms (AOR 2.2, 95\% CI $1.4,3.4)$ in the past 12 months.

Table 3 shows univariate and multivariate analysis of the factors correlated with STI infection. STI prevalence was significantly higher among FSWs who used club drugs in the past 12 months (33.1\%) than those who did not $(21.7 \%, P<$ $0.05)$. STI prevalence was highest among FSWs in Guangzhou (31.2\%) and Hangzhou (26.9\%), followed by Wuhan (24.3\%), Lanzhou (19.2\%), and Changchun $(12.1 \%, P<0.001)$. Other factors significantly associated with higher STI prevalence in univariate analysis included age, marital status, education level, and types of sex work venue. After controlling for 
TABLE 1: Characteristics of FSW who used or did not use club drugs in five cities in China.

\begin{tabular}{|c|c|c|c|c|c|c|}
\hline \multirow{2}{*}{ Characteristics } & \multicolumn{2}{|c|}{ Drug users $(N=118)$} & \multicolumn{2}{|c|}{ Nonusers $(N=1486)$} & \multirow{2}{*}{$\chi^{2}$} & \multirow{2}{*}{$P$ value } \\
\hline & Number & $\%$ & Number & $\%$ & & \\
\hline \multicolumn{7}{|l|}{ Study site } \\
\hline Guangzhou & 69 & 58.5 & 287 & 19.3 & \multirow{5}{*}{138.676} & \multirow{5}{*}{$<0.001$} \\
\hline Hangzhou & 18 & 15.3 & 290 & 19.5 & & \\
\hline Changchun & 1 & 0.8 & 347 & 23.4 & & \\
\hline Lanzhou & 0 & 0 & 349 & 23.5 & & \\
\hline Wuhan & 30 & 25.4 & 213 & 14.3 & & \\
\hline \multicolumn{7}{|l|}{ Venue type } \\
\hline Hotel & 20 & 16.9 & 145 & 9.8 & \multirow{4}{*}{56.901} & \multirow{4}{*}{$<0.001$} \\
\hline Night clubs/KaraOK & 63 & 53.4 & 387 & 26.0 & & \\
\hline Saunas & 16 & 13.6 & 557 & 37.5 & & \\
\hline Hair salons/rental houses & 19 & 16.1 & 397 & 26.7 & & \\
\hline \multicolumn{7}{|l|}{ Age group (years) } \\
\hline $16-20$ & 49 & 41.5 & 291 & 19.6 & \multirow{3}{*}{34.639} & \multirow{3}{*}{$<0.001$} \\
\hline $21-29$ & 59 & 50.0 & 892 & 60.0 & & \\
\hline $30-48$ & 10 & 8.5 & 303 & 20.4 & & \\
\hline \multicolumn{7}{|l|}{ Ethnicity } \\
\hline Han & 110 & 93.2 & 1404 & 94.5 & \multirow{2}{*}{0.328} & \multirow{2}{*}{0.567} \\
\hline Minority & 8 & 6.8 & 82 & 5.5 & & \\
\hline \multicolumn{7}{|l|}{ Marital Status } \\
\hline Never married & 101 & 85.6 & 884 & 59.5 & \multirow{2}{*}{31.435} & \multirow{2}{*}{$<0.001$} \\
\hline Ever married & 17 & 14.4 & 602 & 40.5 & & \\
\hline \multicolumn{7}{|l|}{ Education Level } \\
\hline$\leq$ primary school & 3 & 2.5 & 167 & 11.2 & \multirow{3}{*}{8.731} & \multirow{3}{*}{0.013} \\
\hline Middle school & 73 & 61.9 & 842 & 56.7 & & \\
\hline$\geq$ high school & 42 & 35.6 & 477 & 32.1 & & \\
\hline \multicolumn{7}{|c|}{ Injected drugs in the past 12 months } \\
\hline Yes & 7 & 5.9 & 8 & 0.5 & \multirow{2}{*}{34.331} & \multirow{2}{*}{$<0.001$} \\
\hline No & 111 & 94.1 & 1478 & 99.5 & & \\
\hline \multicolumn{7}{|c|}{ Had STI symptoms in the past 12 months } \\
\hline Yes & 73 & 61.9 & 752 & 50.6 & \multirow{2}{*}{5.547} & 0.019 \\
\hline No & 45 & 38.1 & 734 & 49.4 & & \\
\hline Had STI diagnosis in the pas & & & & & & \\
\hline Yes & 15 & 12.7 & 75 & 5.0 & 12.126 & $<0.001$ \\
\hline No & 103 & 87.3 & 1411 & 95.0 & & \\
\hline
\end{tabular}

demographic and sex work factors, the association between club drug use and STI was no longer significant in multivariable analysis. In the final model, factors associated with higher STI risk included being recruited from Guangzhou (AOR 2.9, 95\% CI 1.8, 4.5), Hangzhou (AOR 2.5, 95\% CI 1.6, 3.8), Wuhan (AOR 2.2, 95\% CI 1.4, 3.4), and Lanzhou (AOR $2.0,95 \%$ CI 1.3 3.1) relative to Changchun, being based in hair salons or rental houses (AOR 1.8, 95\% CI 1.3, 2.5) relative to saunas, aged under 20 (AOR 1.6, 95\% CI 1.1, 2.4) versus above 30 years, and having no more than primary (AOR 1.7, 95\% CI $1.1,2.6$ ) or middle school education (AOR 1.6, 95\% CI 1.2, 2.2).

\section{Discussion}

The prevalence of club drug use and its correlation with sexual risk taking are important issues that have not been closely studied among FSWs in China. Understanding the extent and health effects of club drug use might help identify new modifiable factors that affect FSW's vulnerability to HIV/STI. We conducted a study in five cities in different parts of China to explore the prevalence of club drug use and its association with STI among FSWs. The current study confirms that club drug use is common among FSWs in China. In our study, over $7 \%$ of FSWs reported club drug use during the past year, which is lower than life-time use among FSW in Shandong province of China $[13,14]$. This is probably due to the difference in study locations and design.

The top three most frequently reported club drugs were ketamine, methamphetamine, and ecstasy, which is similar to national patterns and findings among club drug users $[9,16]$. We found significant geographic variations in club drug use. FSW in Guangzhou, Wuhan, and Hangzhou reported more 
TABLE 2: Factors associated with club drug use among FSWs in five cities in China $(N=1604)$.

\begin{tabular}{|c|c|c|}
\hline Characteristics & $\begin{array}{c}\text { Univariate analysis } \\
\text { OR }(95 \% \mathrm{CI})\end{array}$ & $\begin{array}{c}\text { Multivariate analysis } \\
\text { AOR }(95 \% \mathrm{CI})\end{array}$ \\
\hline \multicolumn{3}{|l|}{ Study site } \\
\hline Guangzhou & $3.9(2.3,6.7)$ & $3.2(1.8,5.8)$ \\
\hline Hangzhou & 1.0 & 1.0 \\
\hline Changchun & $0.1(0.01,0.4)$ & $0.1(0.01,0.5)$ \\
\hline Lanzhou & 0 & 0 \\
\hline Wuhan & $2.3(1.2,4.2)$ & $3.5(1.8,7.0)$ \\
\hline \multicolumn{3}{|l|}{ Venue type } \\
\hline Hotel & $4.8(2.4,9.5)$ & $1.1(0.5,2.4)$ \\
\hline Night clubs/KaraOK & $5.7(3.2,10.0)$ & $2.8(1.5,5.1)$ \\
\hline Saunas & 1.0 & 1.0 \\
\hline Hair salons/rental houses & $1.7(0.8,3.3)$ & $0.8(0.4,1.7)$ \\
\hline \multicolumn{3}{|l|}{ Age group (years) } \\
\hline $16-20$ & $5.1(2.5,10.3)$ & $2.4(1.0,6.0)$ \\
\hline $21-29$ & $2.0(1.0,4.0)$ & $1.3(0.6,3.0)$ \\
\hline $30-48$ & 1.0 & 1.0 \\
\hline \multicolumn{3}{|l|}{ Ethnicity } \\
\hline Han & $0.8(0.4,1.7)$ & \\
\hline Minority & 1.0 & \\
\hline \multicolumn{3}{|l|}{ Marital status } \\
\hline Never married & $4.05(2.40,6.83)$ & \\
\hline Ever married & 1.0 & \\
\hline \multicolumn{3}{|l|}{ Education level } \\
\hline$\leq$ primary school & 1.0 & 1.0 \\
\hline Middle school & $4.8(1.5,15.5)$ & $5.1(1.5,17.4)$ \\
\hline$\geq$ high school & $4.9(1.5,16.0)$ & $6.8(1.9,23.6)$ \\
\hline \multicolumn{3}{|c|}{ Injected drugs in the past 12 months } \\
\hline Yes & $11.7(4.1,32.7)$ & $24.4(6.2,96.8)$ \\
\hline No & 1.0 & 1.0 \\
\hline \multicolumn{3}{|c|}{ Had STI symptoms in the past 12 months } \\
\hline Yes & $1.6(1.1,2.3)$ & $2.2(1.4,3.4)$ \\
\hline No & 1.0 & 1.0 \\
\hline \multicolumn{3}{|c|}{ Had STI diagnosis in the past 12 months } \\
\hline Yes & $2.7(1.5,4.9)$ & \\
\hline No & 1.0 & \\
\hline
\end{tabular}

OR, odds ratio; AOR, adjusted odds ratio; CI, confidence interval; STI, sexually transmitted infection.

club drug use than FSWs in Changchun and Lanzhou. This is generally consistent with the drug transmission routes in China $[8,16]$. Additionally, FSWs in Guangzhou, Wuhan, and Hangzhou where local economy is more developed might be able to afford drug use. It could also be due to the fact that club drug use was more prevalent among clients in these areas [9]. Club drug use was more prevalent among younger and better educated FSWs, which is consistent with national patterns and findings of other studies $[9,13,14,17,18]$. Club drug use was found to be associated with injecting drug use and history of STI. Other studies have also found that FSWs who used club drugs tend to have more risk behaviors [13, 14, 17, 18]. Prevention programs will need to account for club drug use in shaping risk patterns and design appropriate intervention measures.
We found a high prevalence of syphilis, NG, and CT infection among FSWs and STI prevalence was significantly higher among FSWs who used club drugs (33.1\%) than those who did not use them $(21.7 \%)$. This is consistent with findings of other studies conducted in China and abroad $[13,14,17,18]$. Club drug use can elevate the risk of HIV/STI through unprotected sexual intercourse, trauma from prolonged intercourse, and less control of condom use under influence $[3,4]$. FSWs who use club drugs may be part of a high-risk sexual network. Clients preferring sex without condoms may be more likely to seek out FSWs who use drugs to offer drugs in exchange for unprotected sex [17]. Since HIV is increasingly spreading through sexual activities in China, club drug use could potentially further fuel the epidemic in China if effective timely interventions are not taken. Current 
TABLE 3: Factors associated with sexually transmitted infection among FSWs in China $(N=1604)$.

\begin{tabular}{|c|c|c|c|}
\hline Characteristics & $\begin{array}{c}\text { STI positive } \\
N(\%)\end{array}$ & $\begin{array}{c}\text { Univariate analysis } \\
\text { OR }(95 \% \text { CI })\end{array}$ & $\begin{array}{c}\text { Multivariate analysis } \\
\text { AOR }(95 \% \text { CI })\end{array}$ \\
\hline Total & $362(22.6)$ & & \\
\hline \multicolumn{4}{|l|}{ Study site } \\
\hline Guangzhou & $111(31.2)$ & $3.3(2.2,4.9)$ & $2.9(1.8,4.5)$ \\
\hline Hangzhou & $83(26.9)$ & $2.7(1.8,4.0)$ & $2.5(1.6,3.8)$ \\
\hline Changchun & $42(12.1)$ & 1.0 & 1.0 \\
\hline Lanzhou & $67(19.2)$ & $1.7(1.1,2.6)$ & $2.0(1.3,3.1)$ \\
\hline Wuhan & $59(24.3)$ & $2.3(1.5,3.6)$ & $2.2(1.4,3.4)$ \\
\hline \multicolumn{4}{|l|}{ Venue type } \\
\hline Hotel & $42(25.5)$ & $1.8(1.2,2.7)$ & $1.1(0.7,1.8)$ \\
\hline Night clubs/KaraOK & $111(24.7)$ & $1.7(1.2,2.3)$ & $1.2(0.9,1.7)$ \\
\hline Saunas & $93(16.2)$ & 1.0 & 1.0 \\
\hline Hair salons/rental houses & $116(27.9)$ & $2.0(1.5,2.7)$ & $1.8(1.3,2.5)$ \\
\hline \multicolumn{4}{|l|}{ Age group (years) } \\
\hline $16-20$ & $106(31.2)$ & $2.0(1.4,2.8)$ & $1.6(1.1,2.4)$ \\
\hline $21-29$ & $197(20.7)$ & $1.1(0.8,1.6)$ & $1.1(0.8,1.5)$ \\
\hline $30-48$ & $59(18.8)$ & 1.0 & 1.0 \\
\hline \multicolumn{4}{|l|}{ Ethnicity } \\
\hline Han & $343(22.7)$ & $1.1(0.7,1.8)$ & \\
\hline Minority & $19(21.1)$ & 1.0 & \\
\hline \multicolumn{4}{|l|}{ Marital status } \\
\hline Never married & $247(25.1)$ & $1.5(1.1,1.9)$ & \\
\hline Ever married & 115 (18.6) & 1.0 & \\
\hline \multicolumn{4}{|l|}{ Education level } \\
\hline$\leq$ primary school & $45(26.5)$ & $1.8(1.2,2.7)$ & $1.7(1.1,2.6)$ \\
\hline Middle school & $229(25.0)$ & $1.6(1.2,2.2)$ & $1.6(1.2,2.2)$ \\
\hline$\geq$ high school & $88(17.0)$ & 1.0 & 1.0 \\
\hline \multicolumn{4}{|c|}{ Used club drugs in the past 12 months } \\
\hline Yes & $39(33.1)$ & $1.8(1.2,2.7)$ & $1.3(0.8,2.0)$ \\
\hline No & $323(21.7)$ & 1.0 & 1.0 \\
\hline \multicolumn{4}{|c|}{ Consistent condom use with clients last month } \\
\hline Yes & $201(23.7)$ & $1.2(0.9,1.5)$ & \\
\hline No & $161(21.3)$ & 1.0 & \\
\hline
\end{tabular}

OR, odds ratio; AOR, adjusted odds ratio; CI, confidence interval; STI, sexually transmitted infection.

intervention efforts should recognize the emerging epidemic of club drug use and increase the understanding of risk associated with club drug use.

We also found that FSWs under age 20 had significantly higher risk of STI. Young FSW may have less knowledge and experience with STI prevention or may be more susceptible to some STIs due to cervical ectopy following sexual initiation [19-21]. On the other hand, when controlling for demographic and sex work factors in multivariable analysis, the association between club drug use and STI was no longer significant. This is probably owing to the concurrent high prevalence of club drug use and STI among young FSWs. Club drugs meet the psychological characteristics of young people (i.e., curiosity and excitement) and are often perceived as of little or no harm [9]. Additionally, untreated STI can increase the risk of HIV acquisition and transmission beside causing serious adverse health outcomes [22]. Therefore, the dual high prevalence of club drug use and STI among young FSWs underscores the urgency to establish a coordinated and better targeted intervention program to jointly address drug use and safe sex issues.

We also found that the types of sex work venues were associated with club drug use and STI. FSWs based at night clubs and KaraOKs reported much higher club drug use, while FSWs at low-end venues like hair salons and rental houses had higher STI rates. Other studies have also found more club drug use among club-based FSWs and higher STI rates among FSWs at low-end venues [14, 17, 21]. This suggests that sex work venues are important focal points for club drug use and STI transmission. Venue-level interventions appropriate for different types of venues are urgently needed to curtail the intersection of club drug use and STI, especially among young FSWs and those based at low-end venues. 
Several limitations of this study should be noted. First, a convenient sample design was employed to recruit FSWs at venues, which means that our sample may not be a good representation of the target population. Secondly, the behavioral data were collected through self-report which might be affected by misreporting bias. Overreporting of condom use by FSWs who used drugs could be the probable reason that no statistically significant association was observed between club drug use and condom use with clients. Thirdly, drug use with different types of sexual partners and sex under the influence of drug use were not explored in the study. More studies are needed to fully understand the context and effect of club drug use to better design intervention programs.

In conclusion, we found high prevalence rates of club drug use and STI among FSWs in China, especially among FSWs under age 20. FSW who used club drugs had more risk behaviors and higher STI rates. Club drug use has the potential to accelerate the sexual transmission of HIV/STI in China. Current prevention programs should recognize the potential of an emerging epidemic of club drug use among FSWs and raise the awareness of risks associated with club drug use. A coordinated risk reduction framework to address the intersection of club drug use and unsafe sex is urgently needed, especially those aimed at young FSWs. More studies are needed to further understand the contexts including sexual partnerships and work environments that may shape drug use patterns among FSW in order to design better targeted prevention messages.

\section{Disclosure}

The funding organization had no role in study design, or the collection, analysis, and interpretation of data.

\section{Conflicts of Interest}

All authors declare no conflicts of interest.

\section{Acknowledgments}

The authors would like to thank the staff who worked in the study sites for recruiting the participants, collecting the specimens, and conducting the interviews. They thank all the staff at National STD Reference Laboratory for doing the tests. The authors are also very grateful to all participants of this study for their cooperation. This study was supported by PUMC Youth Fund and the Fundamental Research Funds for the Central Universities (3332015077).

\section{References}

[1] M. Kleiman and J. Hawdon, "World Drug Report 2016," United Nations Office on Drugs and Crime, 2011, United Nations Publication, Sales NO. E16. XI.7.

[2] P. I. Dargan and D. M. Wood, "Recreational drug use in the asia pacific region: improvement in our understanding of the problem through the UNODC programmes," Journal of Medical Toxicology, vol. 8, no. 3, pp. 295-299, 2012.
[3] J. Lorvick, P. Bourgois, L. D. Wenger et al., "Sexual pleasure and sexual risk among women who use methamphetamine: a mixed methods study," International Journal of Drug Policy, vol. 23, no. 5, pp. 385-392, 2012.

[4] W. S. Cheng, R. S. Garfein, S. J. Semple, S. A. Strathdee, J. K. Zians, and T. L. Patterson, "Differences in sexual risk behaviors among male and female HIV-seronegative heterosexual methamphetamine users," American Journal of Drug and Alcohol Abuse, vol. 35, no. 5, pp. 295-300, 2009.

[5] L. N. Drumright, T. L. Patterson, and S. A. Strathdee, "Club drugs as causal risk factors for HIV acquisition among men who have sex with men: a review," Substance Use and Misuse, vol. 41, no. 10-12, pp. 1551-1601, 2006.

[6] Centers for Disease Control and Prevention, "Methamphetamine use and HIV risk behaviors among heterosexual men-preliminary results from five northern California counties, December 2001-November 2003," Morbility Mortality Weekly Report, vol. 55, no. 10, pp. 273-277, 2006.

[7] H. L. Chen, J. X. Zhang, Q. Xu, Y. X. Dai, and Y. L. Huang, "Synthetic drug boom: potential threat to HIV/AIDS transmission in China," Sexually Transmitted Diseases, vol. 41, no. 10, p. 618, 2014.

[8] Y. Ding and N. He, "Club drugs and HIV/STI infection: a new public health concern in China," Fudan University Journal of Medical Sciences, vol. 39, no. 6, pp. 551-557, 2012.

[9] National Narcotics Control Commission, Ministry of Public Security of People's Republic of China: Annual Report on Drug Control in China (2014), Beijing, China, 2014, http://www.mps .gov.cn/n2255079/n4242954/n4866636/n4866640/c4878933/ content.html.

[10] MOH/UNAIDS/WHO: 2011 Estimates of HIV/AIDS Epidemic in, Beijing, China, China Ministry of Health, 2011.

[11] X. Chen, X. Li, J. Zheng et al., "Club drugs and HIV/STD infection: an exploratory analysis among men who have sex with men in Changsha, China," PLoS ONE, vol. 10, no. 5, Article ID e0126320, 2015.

[12] S. Liu and R. Detels, "Recreational drug use: an emerging concern among venue-based male sex workers in China," Sexually Transmitted Diseases, vol. 39, no. 4, pp. 251-252, 2012.

[13] M. Liao, Z. Jiang, X. Zhang et al., "Syphilis and methamphetamine use among female sex workers in Shandong Province, China," Sexually Transmitted Diseases, vol. 38, no. 1, pp. 57-62, 2011.

[14] M. Liao, S. Su, K. Yan et al., "Dual epidemics of drug use and syphilis among chinese female sex workers: results of right consecutive cross-sectional surveys from 2006 to 2013 in Qingdao, China," AIDS and Behavior, vol. 20, no. 3, pp. 655-666, 2016.

[15] J. Li, N. Jiang, X. Yue, and X. Gong, "Vaginal douching and sexually transmitted infections among female sex workers: a cross-sectional study in three provinces in China," International Journal of STD and AIDS, vol. 26, no. 6, pp. 420-427, 2015.

[16] Y. Ding, N. He, W. Zhu, and R. Detels, "Sexual risk behaviors among club drug users in Shanghai, China: prevalence and correlates," AIDS and Behavior, vol. 17, no. 7, pp. 2439-2449, 2013.

[17] D. Kang, M. Liao, Z. Jiang et al., "Commercial sex venues, syphilis and methamphetamine use among female sex workers," AIDS Care-Psychological and Socio-Medical Aspects of AIDS/HIV, vol. 23, no. 1, pp. 26-36, 2011.

[18] M.-C. Couture, J. L. Evans, N. S. Sothy et al., "Correlates of amphetamine-type stimulant use and associations with HIVrelated risks among young women engaged in sex work in 
Phnom Penh, Cambodia," Drug and Alcohol Dependence, vol. 120, no. 1-3, pp. 119-126, 2012.

[19] A. E. Pettifor, A. N. Turner, K. Van Damme et al., "Increased risk of chlamydial and gonococcal infection in adolescent sex workers in Madagascar," Sexually Transmitted Diseases, vol. 34, no. 7, pp. 475-478, 2007.

[20] M. L. Rekart and R. C. Brunham, "Epidemiology of chlamydial infection: are we losing ground?" Sexually Transmitted Infections, vol. 84, no. 2, pp. 87-91, 2008.

[21] X.-S. Chen, Y.-P. Yin, G.-J. Liang et al., "The prevalences of Neisseria gonorrhoeae and Chlamydia trachomatis infections among female sex workers in China," BMC Public Health, vol. 13, no. 1, article no. 121, 2013.

[22] D. T. Fleming and J. N. Wasserheit, "From epidemiological synergy to public health policy and practice: The contribution of other sexually transmitted diseases to sexual transmission of HIV infection," Sexually Transmitted Infections, vol. 75, no. 1, pp. 3-17, 1999. 


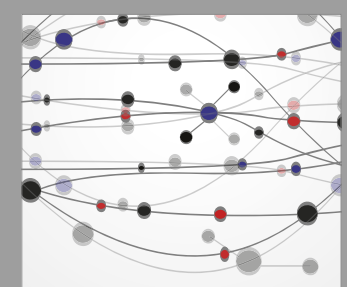

The Scientific World Journal
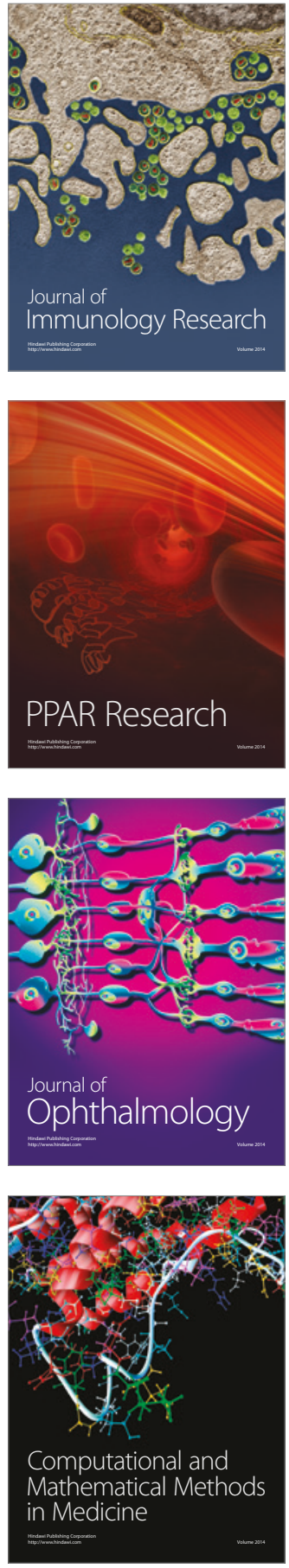

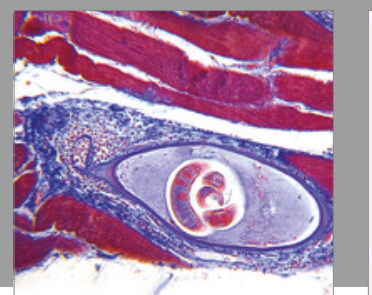

Gastroenterology Research and Practice
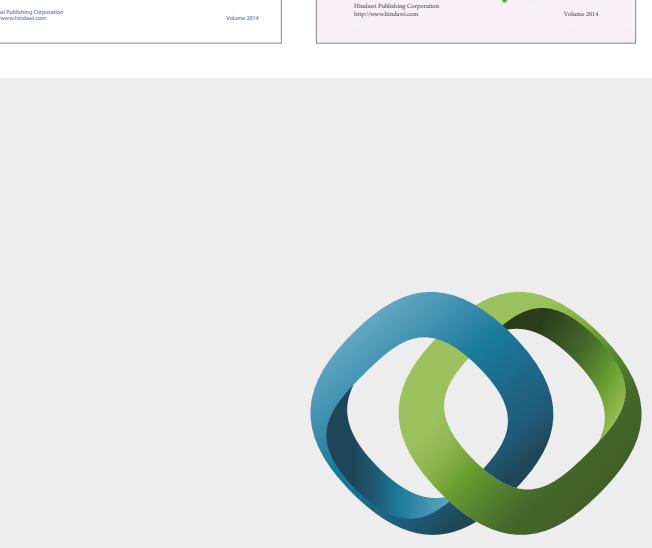

\section{Hindawi}

Submit your manuscripts at

https://www.hindawi.com
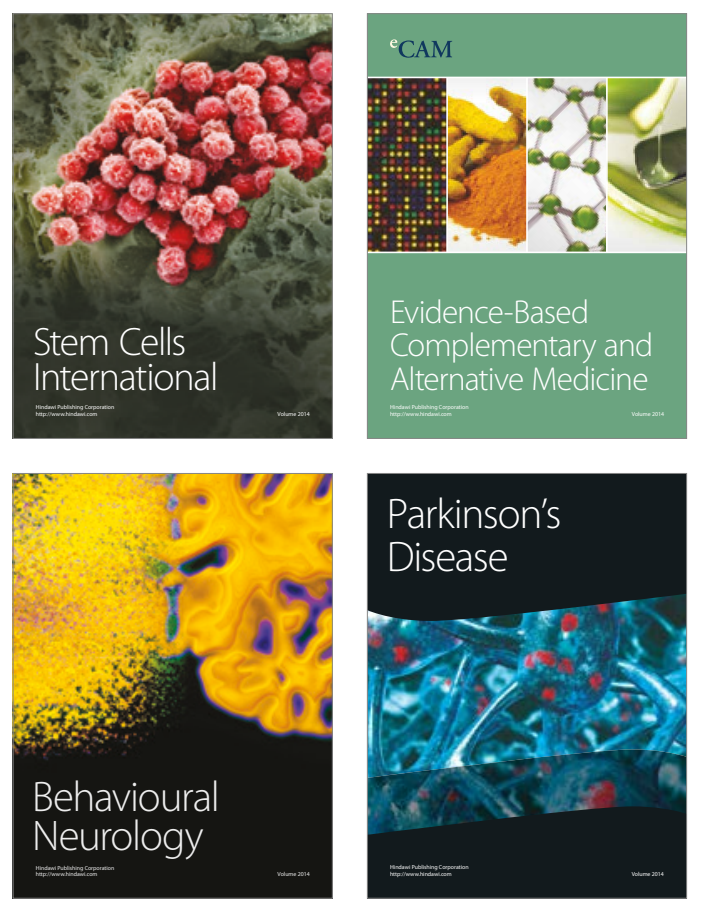
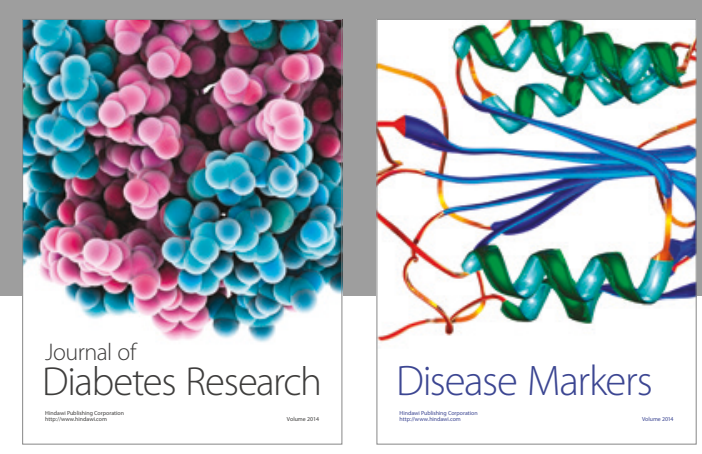

Disease Markers
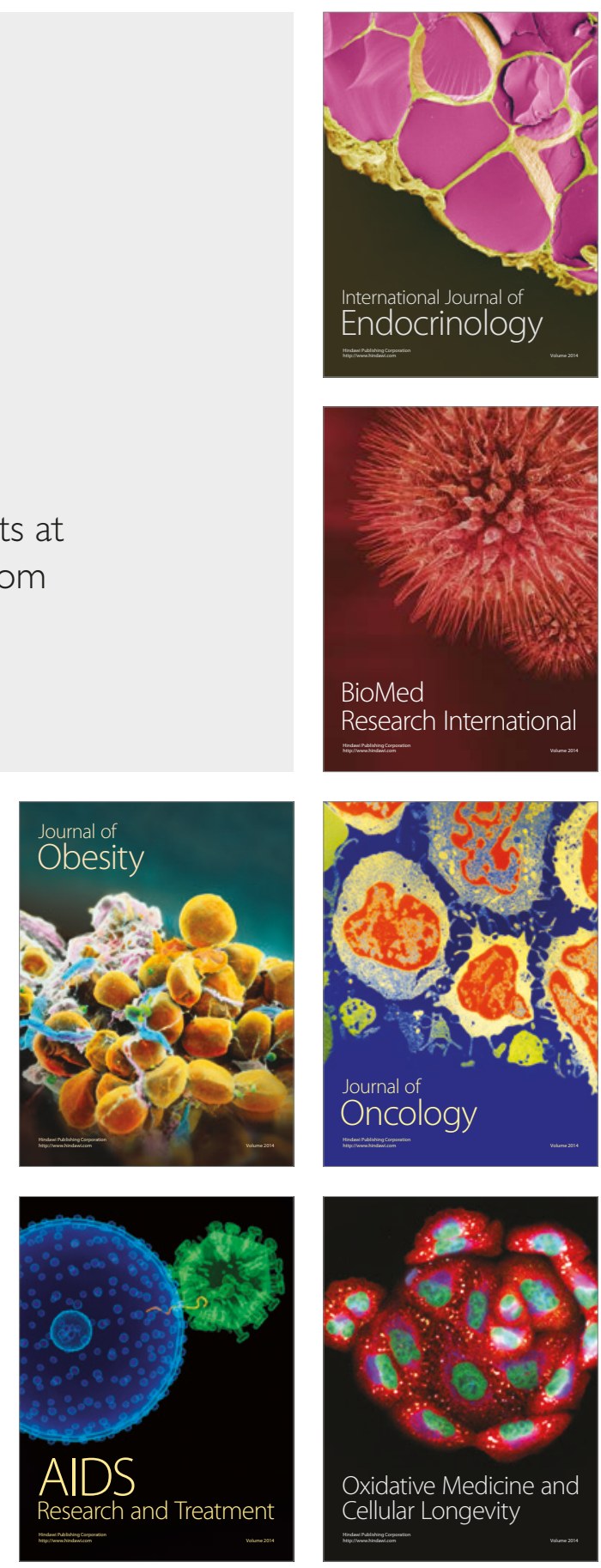